\title{
ОЦЕНКА ТЕХНИЧЕСКОГО СОСТОЯНИЯ ГАЗОТУРБИННОЙ УСТАНОВКИ В СОСТАВЕ ГАЗОПЕРЕКАЧИВАЮЩЕГО АГРЕГАТА
}

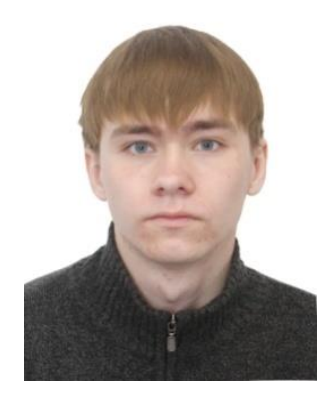

\author{
Е.А. Заславский, студент \\ e-mail: egor.zaslawsky@yandex.ru \\ ФГАОУ ВО «Уральский федеральный университет» \\ В.Л. Блинов, канд. техн. наук, доц. \\ кафедры «Турбины и двигатели» \\ e-mail: vithomukyn@mail.ru \\ ФГАОУ ВО «Уральский федеральный университет»
}

В отечественных трубопроводных газотранспортных системах эксплуатация и техническое обслуживание газотурбинных газоперекачивающих агрегатов осуществляются в соответствии с текущим количеством эквивалентных рабочих часов центробежных газовых компрессоров и газовых турбин. Современные условия эффективного использования энергетических ресурсов требуют проведения процедуры обслуживания в соответствии с текущими характеристиками оборудования, осуществление которой невозможно без определения коэффициента технического состояния газотурбинной установки. В данной статье описана методика определения эффективной мощности газотурбинного газоперекачивающего агрегата по штатно-измеряемым параметрам. Воспроизведены математические модели турбины по рассматриваемому подходу. Представлены результаты испытаний газотурбинной установки на объекте эксплуатации, а также их анализ. Проанализированы вопросы оценки и прогнозирования технического состояния газотурбинной установки с использованием рассматриваемой методики.

Ключевые слова: газоперекачиваюший агрегат, газотурбинная установка, техническое состояние, параметрическая диагностика

\section{ВВЕДЕНИЕ}

Оценка технического состояния газовых турбин, равно как и любого оборудования, имеет особую важность для оптимальной загрузки, своевременного обслуживания, повышения наработки на отказ и увеличения общего срока службы. Тем не менее существует не так много систем и алгоритмов, направленных именно на онлайн-мониторинг эффективности и коэффициента деградации данного оборудования в течение жизненного цикла. Ключевым моментом при этом является точное определение фактической мощности газотурбинной установки (ГТУ).

Одним из наиболее распространённых решений для измерения мощности является использование измерителя крутящего момента (ИКМ) на валу силовой турбины между турбиной и нагрузкой. Однако в условиях эксплуатации такой метод крайне затруднителен, так как большинство агрегатов не оснащены ИКМ. Ещё одним решением проблемы может быть измерение мощности, потребляемой газовым компрессором [1]. Такой метод требует тщательного измерения расхода технологического газа.

В любом случае газокомпрессорная станция остаётся слишком сложным комплексным объектом, на котором организация специальных измерений каждого агрегата является крайне трудозатратной. В связи с этим наличие надёжной математической модели, не требующей дополнительного вмешательства в конструкцию оборудования и трубопроводов, имеет высокий потенциал внедрения. 


\section{ОБЪЕКТ ИССЛЕДОВАНИЯ}

В качестве объекта исследования была выбрана одна из самых распространенных ГТУ в составе газоперекачивающих агрегатов (ГПА) газотранспортной системы нашей страны ГТК-10-4 (рис. 1). Всего для нужд газовой промышленности было выпущено более 1000 агрегатов. Установка ГТК-10-4 Невского машиностроительного завода имени В.И. Ленина выполнена по двухвальной регенеративной схеме со свободной силовой турбиной низкого давления, с выходного вала которой снимается крутящий момент на привод центробежного нагнетателя природного газа [2].

Современные условия бережливого производства требуют проведения процедуры технического обслуживания в соответствии с текущими техническими характеристиками оборудования. Для оценки коэффициента технического состояния (КТС) ГТУ используются результаты испытаний. Схема измерений параметров работы ГТУ представлена на рис. 2.

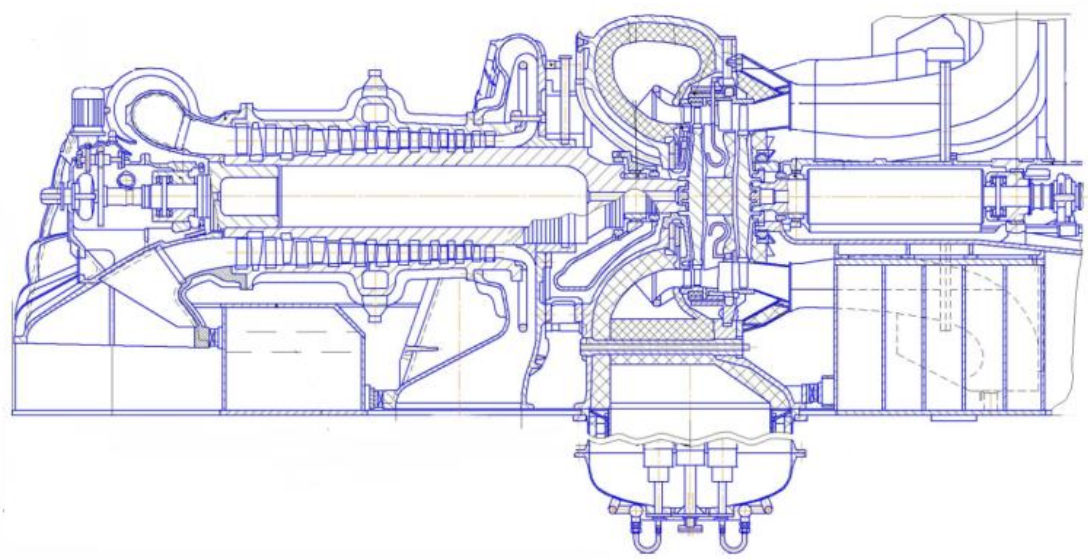

Рисунок 1 - Продольный разрез ГТК-10-4

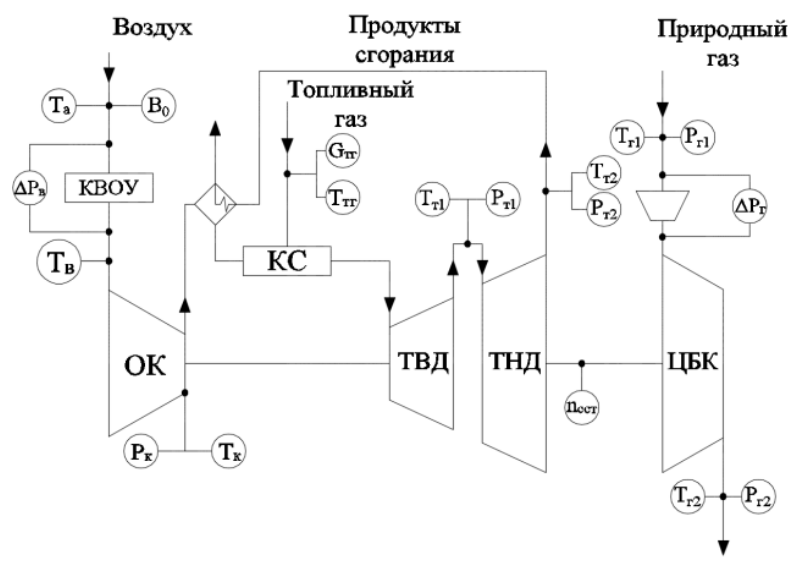

Рисунок 2 - Схема измерения термогазодинамических параметров ГТУ ГТК-10-4

\section{ЦЕЛИ И ЗАДАЧИ ИССЛЕДОВАНИЯ}

Цель исследования заключается в разработке математической модели ГТУ на основе методики определения мощности по параметрам силовой турбины и определения коэффициентов технического состояния газотурбинных установок.

Для решения поставленной цели решены следующие задачи:

- воспроизведены математические модели ГТУ по рассматриваемому подходу;

- обработаны результаты испытаний ГТУ, определены КТС ГТУ по рассматриваемому подходу;

- рассмотрены вопросы оценки и прогнозирования технического состояния ГТУ с использованием рассматриваемой методики. 


\section{МЕТОДЫ ИССЛЕДОВАНИЯ}

В Уральском федеральном университете ведется исследовательский проект [3-7] по определению эффективной мощности ГТУ развиваемой силовой турбиной при помощи использования штатно-измеряемых на ГТУ термодинамических параметров и газодинамических функций для определения расхода газа. Применение данного подхода в эксплуатации позволяет осуществлять определение КТС по мощности ГТУ. Отслеживая динамику КТС во времени, можно контролировать изменение технического состояния ГТУ [8].

Алгоритм метода включает в себя два основных этапа: разработка математической модели ГТУ по параметрам номинального режима работы; проведение и обработка результатов испытаний натурной ГТУ по штатно-измеряемым параметрам с целью определения эффективной мощности и КПД ГТУ с последующей верификацией разработанной модели. После верификации разработанной модели, метод можно использовать для оценки технического состояния ГТУ. Схема алгоритма изображена на рис. 3.

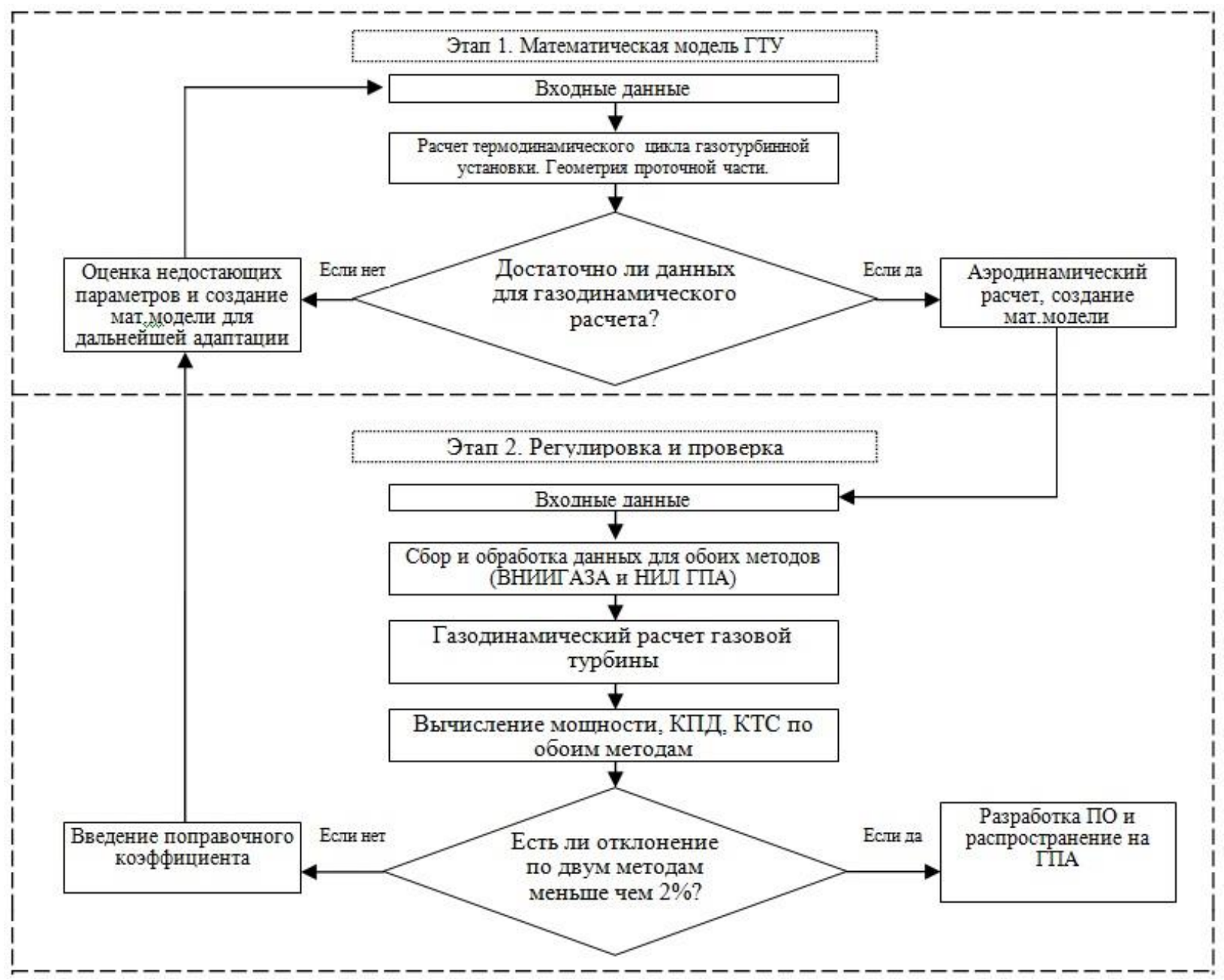

Рисунок 3 - Архитектура оценки технического состояния газотурбинной установки со стандартными измерениями

Входными данными для математической модели на первом этапе являются параметры ГТУ взятые по каталогу, выпущенному ВНИИГАЗом: номинальная мощность $\mathrm{N}_{\mathrm{e}}$, температура продуктов сгорания на входе в турбину высокого давления (ТВД) $\mathrm{T}_{\text {}}$, потери давления во входных и выходных патрубках, степень сжатия компрессора, расход топливного газа, расход циклового воздуха, расход продуктов сгорания за свободной силовой турбиной (CСТ), частоты вращения роторов, температура продуктов сгорания после ССТ. Атмосферное давление и температура окружающей среды. Переменные параметры, принимаемые на основании опыта конструирования и эксплуатации: КПД каждой турбины, КПД камеры сго- 
рания, КПД осевого компрессора, а также механический КПД. Задаются коэффициент, учитывающий разницу расхода продуктов сгорания турбин и циклового воздуха компрессора, коэффициент скорости в лопатках ротора и статора, геометрия реальной проточной части (диаметры и высоты лопаток).

На этапе расчета термодинамического цикла рассчитываются основные параметры: температура и давление после компрессора, удельная работа сжатия, давление и температура на входе и выходе турбин, степень расширения продуктов сгорания в турбинах, удельная работа расширения, удельная теплоемкость рабочего тела и т.д.

Задача состоит в том, чтобы добиться приемлемой сходимости между вычисленными параметрами ГТУ на номинальном режиме с данными, представленными в каталоге ВНИИГАЗ [9].

На этапе газодинамического расчета производится определение полных и статических температур, давлений газа на входе и выходе из каждой ступени турбины, кинематических параметров потока из условия заданной реальной геометрии проточной части и т.д.

Исходными данными для расчета второго этапа являются данные по конкретному режиму работы установки, а также параметры, принимаемые на этапе расчета модели двигателя на номинальном режиме; ометаемые площади на выходе из соплового аппарата турбин, углы выхода потока из соплового аппарата, степени реактивности на среднем диаметре для каждой ступени ССТ, полученные в ходе газодинамического расчета ступеней турбин на этапе разработки математической модели двигателя.

После верификации модели и внедрения ее в эксплуатацию входными данными будут являться параметры по конкретному режиму работы установки. Для использования этих данных в разработанном подходе необходимо организовать их фильтрацию. В первую очередь требуется исключить из анализа режимы пуска и останова ГТУ, а также идентифицировать неустановившиеся режимы работы ГТУ. Для отфильтрованных режимов работы ГТУ осуществляются все расчеты по предложенному алгоритму. Определяются фактические величины мощности ГТУ на данных режимах. После этого необходимо привести все параметры к номинальным условиям. Затем на основании полученных зависимостей определяется располагаемая мощность, КПД и коэффициент технического состояния ГТУ. Организовав сбор и хранение полученных данных, можно отслеживать деградацию технического состояния ГТУ с течением времени, а также оценить качество проведенного ремонта, например, по «сдвигу» характеристики ГТУ. Наличие данных по изменению КТС во времени позволяет спрогнозировать, как изменится состояние установки через определенный период эксплуатации.

\section{РЕЗУЛЬТАТЫ ИССЛЕДОВАНИЯ}

Статистическая информация по пяти агрегатам ГТК-10-4, для которых проведены испытания на объектах их эксплуатации представлена на рис. 4. Все точки посчитаны по представленной методике на основании только штатных измерений с калиброванными измерительными приборами. Представленные на графике линии являются трендами для своей группы точек. Как видно, установки имеют разный коэффициент технического состояния. В основном это связано с тем, что у каждого разная наработка после ремонта. Номинальная температура на выхлопе составляет 780 К при заявленной номинальной мощности ГТК-10-4. Все тренды пересекают вертикальную линию номинальной температуры в разных положениях: 9250, 8620, 7400, 6510 и 6250 кВт соответственно. Таким образом, у агрегата № 1 КТС по мощности 0,925, № $2-0,862$, № $3-0,740$, № $4-0,651$ и № $5-0,625$. Стоит отметить, что парк установок ГТК-10-4 имеет среднюю общую наработку свыше 130000 ч, а в некоторых случаях наработка достигает 200000 ч. На сегодняшний день установки данного типа заменяются на новые. 


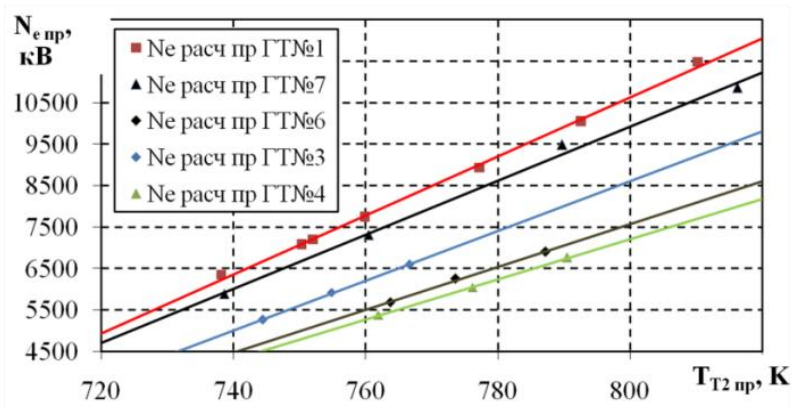

Рисунок 4 - Зависимости изменения эффективной приведенной мощности рассматриваемых ГТУ от приведенной температуры продуктов сгорания за ССТ

По смещению линии тренда можно судить о деградации технического состояния конкретной установки. При этом точное значение мощности ГТУ определять не обязательно, главное - отслеживать ее количественное изменение (например, в \%), и начинать отслеживать не обязательно с «идеального» состояния ГТУ. Данный признак может использоваться в диагностических системах. Для примера, на рис. 5 изображен гипотетический характер смещения характеристик ГТУ в процессе деградации технического состояния (без учета мероприятий по восстановлению технического состояния установки в процессе эксплуатации).
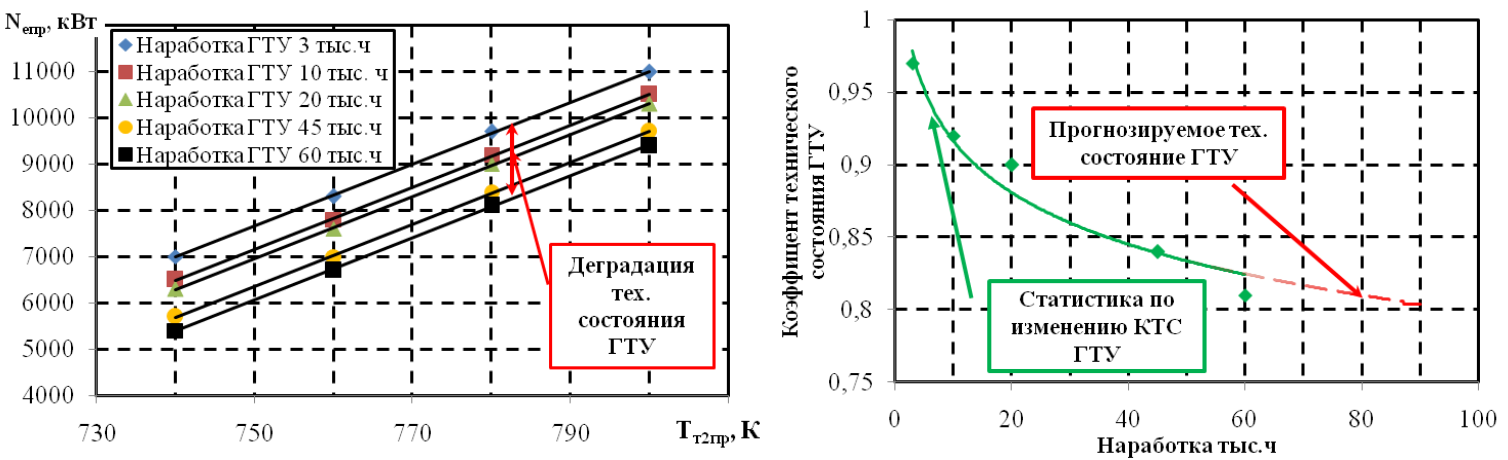

Рисунок 5 - Зависимости изменения эффективной приведенной мощности ГТУ от приведенной температуры продуктов сгорания за ССТ (а) и изменение КТС ГТУ (б) в зависимости от наработки

Предложенная методика оценки технического состояния может быть использована для количественной оценки эффективности ремонтных и восстановительных мероприятий на основании штатно измеряемых параметров. То есть ГТУ может быть испытана до и после проведения обслуживания (промывки компрессора, восстановления радиальных зазоров и пр.) и по результатам зафиксирован эффект от мероприятия.

С использованием данных по изменению КТС ГТУ, а также статистики по дефектам основных узлов ГТУ, можно спрогнозировать вероятное изменение технического состояния установки с течением времени. Для полноты картины текущего состояния ГТУ, а также улучшения точности прогноза, полученные данные параметрической диагностики необходимо рассматривать и анализировать совместно с иными имеющимися способами диагностирования состояния газовой турбины.

\section{ЗАКЛЮЧЕНИЕ}

Для осуществления перехода эксплуатации ГТУ по техническому состоянию, в первую очередь необходимо организовать фильтрацию измеряемых параметров работы установки с целью исключения из расчета неустановившихся режимов (режимы, при которых параметры работы газовой турбины существенно меняются за короткое время).

После фильтрации и определения установившихся режимов работы ГТУ, необходимо произвести расчет согласно разработанным математическим моделям для конкретной установки.

Организовав хранение и сбор вычисляемых и измеряемых данных, следует осуществить их обработку с целью оценки текущего состояния установки и её отдельных узлов, а 
также принятия решения о возможности дальнейшей эксплуатации и прогнозирования деградации технического состояния ГТУ.

Научная новизна работы состоит в описании алгоритма определения технического состояния ГТУ на основе методики определения мощности по параметрам силовой турбины. Практическая значимость работы заключается в определении коэффициентов технического состояния и эффективной мощности по параметрам силовой турбины. Теоретическая значимость результатов работы состоит в подтверждении работоспособности перспективного метода определения эффективной мощности ГТУ по параметрам силовой турбины и оценке деградации технического состояния ГТУ.

\section{СПИСОК ЛИТЕРАТУРЫ}

1. Щуровский, В.А. Методические указания по проведению теплотехнических и газодинамических расчетов при испытаниях газотурбинных газоперекачивающих агрегатов ПР 51-3132394943-99 / В.А. Щуровский [и др.]. - Москва : ВНИИГАЗ, 1999. - 26 с.

2. Главный промышленный портал бизнес России. [Электронный ресурс]. - URL: https://glavportal.com/ (дата обращения: 19.06.2019).

3. Заславский Е.А. Параметрическая диагностика и оценка технического состояния газотурбинных газоперекачивающих агрегатов / Е.А. Заславский, В.Л. Блинов // Энерго- и ресурсосбережение. Энергообеспечение. Нетрадиционные и возобновляемые источники энергии. Атомная энергетика: Международная научно-практическая конференция студентов, аспирантов и молодых ученых, посвященной памяти проф. Данилова Н. И., Екатеринбург, 1014 декабря 2018 г.: материалы. - Екатеринбург, 2018. - С. 203-206.

4. Заславский, Е.А. Анализ методов определения эффективной мощности газотурбинных газоперекачивающих агрегатов / Е.А. Заславский, В.Л. Блинов: материалы международной научно-практической конференции. - Санкт-Петербург: СПбФ НИЦ МС, 2019. № 2. - С. 39-41.

5. Якименко И.С. Оценка технического состояния газотурбинных установок по мощности / И.С. Якименко, В.Л. Блинов, О.В. Комаров // Энерго- и ресурсосбережение. Энергообеспечение. Нетрадиционные и возобновляемые источники энергии: Всероссийская научнопрактическая конференция студентов, аспирантов и молодых ученых с международным участием, Екатеринбург, 12-16 декабря 2016 г.: материалы. - Екатеринбург, 2016. - С. 316-319.

6. OlegV. Komarov, ViacheslavA. Sedunin, VitalyL. Blinov, AlexanderV. Skorochodov. Parametrical diagnostics of gas turbine performance on side at gas pumping plants based on standard measurements // ASME Turbo Expo, Dusseldorf, Germany, 16-20 june 2014. P. 1-8.

7. Заславский Е.А. Сравнение методов определения эффективной мощности газотурбинных газоперекачивающих агрегатов / Е.А. Заславский, В.Л. Блинов // Энерго- и ресурсосбережение. Энергообеспечение. Нетрадиционные и возобновляемые источники энергии. Атомная энергетика: Международная научно-практическая конференция студентов, аспирантов и молодых ученых, посвященной памяти проф. Данилова Н. И. (1945-2015) - Даниловских чтений (Екатеринбург, 9-13 декабря 2019 г.): материалы. - Екатеринбург: УрФУ, 2019. -878 c.

8. Китаев, С. В. Повышение энергетической эффективности работы газоперекачивающих агрегатов: 25.00.19, 05.02.13 : дис. ... канд. техн. наук / Китаев С.В.; Уфимский государственный нефтяной технический университет Шаранское ЛПУ МГ. - Уфа, 2003. - 162 с.

9. Альбом показателей газотурбинных ГПА. - Пос. Развилка (Ленинский р-н, Московская обл.): ВНИИГАЗ, 2006. - 81 с. 


\title{
ASSESSMENT OF THE TECHNICAL CONDITION OF A GAS TURBINE PLANT IN THE COMPOSITION OF A GAS PUMPING UNIT
}

\author{
E.A. Zaslavskiy, student, \\ e-mail: egor.zaslawsky@yandex.ru \\ Ural Federal University \\ V.L. Blinov, PhD, Associate Professor, \\ e-mail: vithomukyn@mail.ru \\ Ural Federal University
}

In domestic pipeline gas transmission systems, operation and maintenance of gas turbine gas pumping units are carried out in accordance with the current number of equivalent working hours of centrifugal gas compressors and gas turbines. Modern conditions for efficient use of energy resources require maintenance procedures in accordance with the current characteristics of the equipment, which is impossible without determining the coefficient of technical condition of the gas turbine installation. This article describes a method for determining the effective power of a gas turbine gas pumping unit based on standard-measured parameters. Mathematical models of the turbine according to the considered approach are reproduced. The results of testing of a gas turbine installation at the operating facility, as well as their analysis, are presented. The issues of evaluating and predicting the technical condition of a gas turbine installation using this technique are considered.

Key words: gas pumping unit, gas turbine unit, technical condition, parametric diagnostics 